\title{
Coping with Infertility: An Explorative Study of South African Women's Experiences
}

\author{
Athena Pedro \\ Psychology Department, University of the Western Cape, Bellville, South Africa \\ Email: aspedro@uwc.ac.za \\ Received 5 January 2015; accepted 20 January 2015; published 23 January 2015 \\ Academic Editor: Chris Constantinou, Stanford University Medical School, USA \\ Copyright (C) 2015 by author and Scientific Research Publishing Inc. \\ This work is licensed under the Creative Commons Attribution International License (CC BY). \\ http://creativecommons.org/licenses/by/4.0/

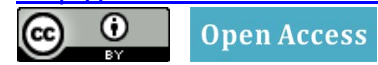

\section{Abstract}

The expectation of getting married and having children is for many individuals a natural part of adult life. Many young people anticipate the prospect of becoming biological mothers and fathers. This expectation of parenthood emanates as individuals and couples are socially groomed to aspire to this social norm. Therefore, infertility can be a very traumatic and tormenting time for many men and women who aspire to conform to these socio-cultural conventions of normative parenthood and who believe that childbearing is central to their lives. Infertility is medically defined as the inability to achieve a pregnancy after a period of at least twelve months of regular sexual intercourse without contraception. For both men and women infertility may present pervasive feelings of incompleteness, a sense of failure and inadequacy. However, infertile women tend to endure a myriad of feeling losses and high levels of suffering and sorrow as a result of their inability to have children. This study explored a sample of South Africa women's experiences of coping with infertility. Utilising a qualitative methodology, a diverse group of 21 married women who were diagnosed with primary infertility were recruited. Semi-structured, in-depth individual interviews were conducted and the data were analysed using thematic analysis. The results of the study indicated that the women reported emotional turmoil characterised by emotions such as disappointment and shock, anger and frustration, a deep sense of sadness and then progressed to experience a sense of acknowledgement that a problem existed. The findings of this study suggest that severe psychological and emotional strain accompany infertility. The coping strategies employed by these women in the study included social withdrawal and women isolating themselves from social events and social gatherings, avoiding pregnant women and women with children, engaging in escapism strategies on both a psychological level and a physical level. Employing an escapism strategy on a psychological level would involve deliberately thinking about strategies to avoid thinking about infertility, pregnancy or babies. Escapism on the physical level would include engaging in activities like shopping, working longer hours, sleeping more than usual, engaging in activities that would occupy an individual to the extent that they cannot think about anything else 
except the activities they are currently engaged in.

Keywords

Infertility, Psychological and Emotional Trauma, Motherhood, Involuntary Childlessness, Coping

\section{Introduction}

The expectation of getting married and having children is for many individuals a natural part of adult life. Many young people anticipate the prospect of becoming biological mothers and fathers [1]. This expectation of parenthood emanates as individuals and couples are socially groomed to aspire to this social norm [2]. Therefore, infertility can be a very traumatic and tormenting time for many men and women who aspire to conform to these socio-cultural conventions of normative parenthood and who believe that childbearing is central to their lives [3]. Infertility is medically defined as the inability to achieve a pregnancy after a period of at least twelve months of regular sexual intercourse without contraception [4]. For both men and women infertility may present pervasive feelings of incompleteness, a sense of failure and inadequacy. However, infertile women tend to endure a myriad of felt losses and high levels of suffering and sorrow as a result of their inability to have children. In addition, they find themselves positioned as outcasts and ostracised due their inability to have children. Involuntarily childless women, through no choice of their own, find themselves unable to conform to the social norms of motherhood. Yet these involuntary childless women are judged according to the same standards as that of women with children as a basis for their gender and social identity. Infertile women have no alternative identity, as their master narrative is that of motherhood. Consequently, infertile women often fall victim to various forms of abuse and disempowerment. Several studies [5] [6] emphasise the issue of the cultural construct of motherhood as important for a woman's social, psychological and physical sense of adequacy and completeness.

When couples experience repeated failure to conceive naturally, they tend to compare themselves with their peers that have conceived and gauge the timeframe from suspension of contraception to conception. Many people assume that they are immune to infertility and often take for granted that fertility is a birth right and their destiny, when in actual fact, the harsh reality is that fertility is a privilege and not everyone will be able to conceive or bear children. Research in sub-Saharan Africa indicates that $20 \%-50 \%$ of couples of reproductive age have a fertility problem and 30\% are diagnosed with infertility [7].

Even though infertility is primarily dealt with medically, the psychological and emotional effects thereof are undeniable. When individuals discover their infertility status, they often experience emotions such as surprise, denial, anger, depression, rejection and guilty feelings of worthlessness [8]. This cycle of emotions is characteristic of feelings such as shock, anxiety and loss of control and denial of non-conception [8]. These are emotional reactions or manifestations of the psychological effects of infertility, which develop into what is often referred to as the "crisis of infertility" [9]. Domar et al. (1993) reported that infertile women revealed psychological distress levels similar to patients with grave medical conditions such as cancer, heart disease and hypertension [10]. Infertility has also been linked to psychological problems such as low self-esteem, depression and anxiety disorders [11]. According to Hasty (2011), women experience emptiness, loneliness, depression, rejection, helplessness, powerlessness and anger as emotional reactions to infertility [12]. Frustration and loss are central themes in the knowledge and experience of infertility. Kubler-Ross' (1969) ground-breaking work in the area of grief is now well recognised in grief counselling and has extended its application to various other traumatic experiences, like infertility [13].

In addition to psychological and emotional stress, it is not uncommon for infertile women to experience marital distress [14]. Given that many couples may view parenthood as being a core goal of the marital union [14], the inability to achieve their envisioned life as a family unit can create animosity and difficulty within the marital dyad. Infertility challenges the endurance and resilience of the marital relationship. It is a perception that infertility will either destroy or solidify the marital union. The manifestation of the infertility nightmare may become present in the loss of intimacy and pleasure derived from sexual intimacy experienced by the couple. It may be replaced with frustration and a dissociative experience that becomes a mere mechanical experience in attaining the goal of conception [15]. 
Couples trying to conceive naturally or undergoing fertility treatments are often required to plan when they will be sexually intimate and having scheduled sex could add further strain on the relationship [15]. The scheduled sex almost becomes a "chore" and as a result many infertile women often describe a dissociative state during sexual intimacy manifested as a body-mind split. This dissociative experience is often described as the infertile women physically present allowing her body to partake in the sexual act as a means of achieving a pregnancy but on the psychological level she is not fully engaged and wanting to be part of this sexually intimate act. A participant in the study referred to this as "consensual rape".

Strain on the marital relationship is further exacerbated when financial aspects of affording treatments are considered and discussed. Also, it is not uncommon for the person who has been diagnosed as infertile to offer a divorce to their fertile spouse so that they at least have an opportunity of bearing a biological child with another partner [16] [17]. As discussed previously, infertility is often identified as a major cause of divorce and abandonment throughout the African continent [18]. With all the emotional and marital strain, it is important to identify the coping mechanisms and strategies employed by these childless couples.

Schmidt, Holstein, Christensen, and Boivin (2005) conducted a study in Denmark, a country in which there is free access to high quality assisted reproductive technology. The study explored coping responses employed by individuals of different occupational social classes [19]. The sample consisted of 1169 women and 1081 men of high, medium and low social classes. The high social class consisted of executives, professionals and mid-level white-collar employees. The medium social class consisted of low-level white-collar employees and skilled workers. Unskilled and semi-skilled employees constituted the low social class [19]. Four coping strategies were examined in the study. The first coping strategy was active-avoidance strategies such as avoiding children or pregnant women. The second strategy was active-confronting strategies such as showing their feelings and asking others for advice. The third strategy was passive avoidance strategies such as not making a deliberate effort to interact with fertile women or pregnant women. The final strategy involved meaning-based coping; such as praying or finding other goals in life [19].

The study found that women from lower social classes employed more active-confronting coping and more meaning-based coping strategies than women from the highest social class [19]. Men and women from medium social classes employed less active avoidant coping and more passive avoidant coping than higher social classes [19]. The researchers concluded that coping might be learnt from one's reference group or social networks [19]. In addition, to social networks, the coping strategies between the genders also revealed differences.

Lee et al. (2000) hypothesised that men and women employed different coping strategies and therefore developed the Coping Scale for Infertile Couples (CSIC) that was gender sensitive. The CSIC is a 5-point scale with four sub-sections. The first two subsections are "increasing space" and "regaining control". "Increasing space" referred to when the infertile individual or couple increased space between themselves and their fertility problems, usually by avoidance or keeping busy, whereas "regaining control" meant regaining control over infertility or its treatment and this may be done by educating oneself regarding infertility [20]. The third subsection of this scale is entitled "being the best", this refers to when one partner unintentionally initiates behaviours that make the couple feel that they are the best, such as keeping a positive attitude [20]. The final subsection of the scale entitled "sharing the burden", this refers to when one partner shares their infertility related fears and frustrations with one's partner [20].

The researchers found that wives tended to use coping strategies such as "increasing space" and "sharing the burden" more often, whereas husbands mostly employed "being the best" as their coping strategy of choice [20]. This indicates that men and women employ different coping strategies and therefore couple's counselling may assist couples in dealing with their infertility by offering a counselling model that is more compatible coping strategy However, this study only explores coping mechanisms of couples who are involuntary childless.

\section{Aims and Objectives of the Study}

This study explored the experiences of infertile women and sought to identify their coping strategies in dealing with their infertility. The primary objective of the study was to explore how infertile women experience infertility and to identify their coping strategies and techniques they used to cope with the hardship of infertility. By identifying these experiences of infertility and the coping strategies employed, the necessary recommendations may be submitted to other involuntary childless couples as well as health practitioners. These health practitioners working with infertile couples may feel encourage to share this information on coping with infertility with 
their patients.

\section{Method}

A qualitative methodological approach was used for this study as it provides personal descriptive accounts of how involuntary childless women experience infertility and also identified the coping strategies employed by these women. These subjective accounts provided in-depth insight into these women's experiences of infertility and how they coped with their infertility. Applying a social constructionist theory abetted in understanding how involuntary childless women in our study interpreted, responded to and attached meaning to their experience of infertility as well as how they coped with it.

\subsection{Study Participants}

To be eligible to participate in the study, the participants had to be married or at least in a committed relationship; and present with primary infertility. The snowball technique was used to recruit these participants. As potential participants were identified a screening questionnaire was used to determine whether these women matched the sample criteria. The participants were invited to a briefing session whereby they were informed about the study aims, procedures and ethical considerations. As the aim was to recruit a diverse sample, further consideration was given to the distributions of ethnic (black, white or coloured ancestry) groups, the participants' mother tongue language/s (i.e. Afrikaans, English and Xhosa) and religion (Christian, Muslim or Indian). A sample of 21 women were recruited and participated in the study. Initially it was intended to recruit a sample of 30 participants however saturation point was reached at the 21st interview.

\subsection{Data Collection and Study Instruments}

The most appropriate data collection method for this study was semi-structured individual interviews as it allows the participants flexibility and creates space for the participants to share their story in an unrestrictive manner. The interview schedule was designed largely based on literature and theoretical content. The key research questions posed were of an exploratory and descriptive nature. The questions probed specifically about their experiences of infertility and their coping strategies employed in managing their infertility. Some of the questions asked were "how did you come to realise that you were having difficulty falling pregnant, what does it mean to you to be a woman, what does infertility mean to you, how did you cope with being infertile, what kind of coping strategies did you use to manage your infertility, what kind of support did you have, what kind of support did you need, do you feel you employed the appropriate coping strategies,”. The interview guide was pretested to ensure content validity and also assisted with estimating time frames in conducting the interviews. The duration of the interview was approximately one hour. Prior to the commencement of the interview, a debriefing session was held. In this session, informed consent was obtained, each of the participants were handed a copy of the interview guide to peruse and then explained how the interview process would unfold. The final phase of the interview involved another debriefing session. The purpose of this post-debriefing session was to get a sense of the participants' emotional state and frame of mind, to alleviate any strain that may have been caused from any sensitive questions asked in the interview. The debriefing session provided the participants with a safe space to talk about how they felt sharing their story and how they experienced the interview. All of the participants indicated that they were very pleased to share their story and felt very positive about making a contribution to the study and to the infertility body of knowledge as a whole. The pre and post debriefing sessions were approximately 20 minutes each. The interviews were either conducted at the participant's home or at a neutral venue such as a local coffee and snack bar.

\subsection{Data Analysis}

The levels of analysis embarked upon in this study were preliminary analysis, thematic analysis, coding, and interpretation. The first entry into analysis was to critically assess the data as it was collected, ascertain gaps in the information, and to commence with various concepts and establish a framework to assess if the data collected provided more information on issues relating to the research topic. Each interview transcription was read, summarized and analysed by means of developing themes. The themes that were established with the preliminary analysis were scrutinized once data had become saturated and an extensive view of the topic acquired. Each 
theme was placed in a specific file once it had been contextualised. There were essentially five major steps that made up the levels of analysis. The steps were; data organisation and reduction, thematic analysis, coding, interpretation and conclusion drawing.

\subsection{Ethical Considerations}

The ethical considerations adhered to in this study ranged from informed consent; minimization of potential harm/deprivation of benefits; and confidentiality and protection of privacy. The proposal of the research study served at the University of the Western Cape Ethics Committee and permission was granted to conduct the current study. All of the participants voluntarily participated in the study; none of the participants were coerced or manipulated into sharing their subjective experiences of infertility. The participants were given the option of withdrawing from the study at any time and also given the assurance that any questions deemed too difficult to answer could be omitted. Participants were also provided with a psychological counsellor if required.

\section{Results}

\subsection{Demographics of the Sample}

The sample comprised of a total of 21 women. The women ranged in age from twenty six to forty-one years, with the average age being 30 years old. All of the participants are married, 15 of the participants had a postmatric qualification while the remaining six participants had a matric qualification. English was the first language for 16 of the participants while three of the participants were bilingual with both English and Afrikaans languages, and the remaining two participants spoke Afrikaans as a mother tongue but had good proficiency in English. Only four of the participants were Muslim, while the remaining 17 of the participants were Christian in religion. About 19 of the participants were employed full time, only two of the participants were unemployed. While 11 of the participants were of the white race, the remaining 10 participants were of the coloured race. Of the 21 participants recruited and interviewed, only 11 of the participants disclosed that they had received some form of counselling.

\subsection{Themes Identified}

\section{Coping with Infertility}

\section{1) Disclosure: to tell or not to tell.}

Since infertile women are put under enormous social pressure and stress to reproduce, it is perhaps easy to understand why some women choose to remain silent about their infertility. However, it is interesting to note why and to whom these women chose to disclose their infertility status to. For the participants in this study, the decision to disclose their infertility to family relatives and friends was met with great dilemma. At least half of the participants in this study disclosed their infertility status but only to what they considered to be "close" family and friends. Other relatives and friends, to whom they were not considered "close", were not told about their infertility as they only disclosed their status to people whom they felt they could trust. This "trust" referred to people not making fun of them and not discussing their "private" infertility matter with other people.

"I felt that I could talk about my infertility to some people but not others. It would have to be people whom I could trust. People that I know won't tell other people about it and that they won't make fun about it behind my back. I felt like I needed to tell someone and talk about it to someone. Even though it is very personal, I needed the support."

"At the beginning when this whole thing started I couldn't talk about it but then as time went by say 8 months, I needed to talk about it to someone. It had to be someone very close to me, someone I knew I could trust to keep this quiet and who would understand."

"This was a very difficult time for me and you know, you need a good friend, someone to support you. I needed to tell my friend but I only told her because I knew I could trust her. It was only a few months afterwards when I finally told some of my family members who were close to me. But it's because I had the support from my husband and friend, you see."

Trust was the main requirement for the participants in disclosing their infertility status. The disclosure was only made once the participants felt confident that the person they are disclosing to could be trusted not to divulge this "secret" or that they would be made fun of. 
The participants were asked to retrospectively consider if they were happy that they chose to disclose their status and if they felt that they made the right decision to disclose. Of the participants who did disclose, only one participant was happy with the decision. The other participants expressed regret as they felt that it later added more pressure, as their confidants would consistently inquire about their infertility status and condition. This habitual enquiry was described as being a frustration as every upcoming cycle and cycle that passed would be earmarked and discussed at length. As a result the participants felt regretful in sharing their status with others. Whilst they acknowledge that the enquiry was motivated by mere concern, the effect of the enquiry has sparked a sense of annoyance and raised the level of aggravation for the participants. In hindsight, the participants revealed that if they could do it all over again they would not have revealed their infertility status to friends or family members for that matter.

"initially when we told them we expected support and comfort not frustration. But after the constant discussion about it, I mean we spoke it to death I really started to become annoyed of the ... pestering, you know. I was ever sorry I told them."

"I really did not expect that kind of behaviour from them and I remember saying to myself "what were you thinking telling them about it" but I thought it was a good move. But as time went by they started to monitor my menstrual cycle and before the cycle start they would say 'its almost time' or when I'm ovulating they would say 'ooh we better cut our night short and leave early because tonight is your special night'. Maybe they thought they were helping but I was getting aggravated."

"We should never have told them because they add more stress and frustration than good."

Whilst the intentions of these women were to receive support and care, their experience of disclosure to family members and friends proved to be more challenging than supportive. The participants who chose not to disclose their status were asked to elaborate on their decision for non-disclosure. They felt that their experience of non-conception was difficult enough and felt that the matter was just too personal to discuss with others. At the time of dealing with this difficult experience they felt that they did not have the energy to explain to others the situation at hand. They also felt that they could not trust people with this kind of information, as they feared being judged or ostracised. There is a common perception that childless individuals are stigmatised by society. According to [21] infertile women felt that disclosure led others to think less of them and that their infertility represented failure. Many of the participants felt that keeping the infertility ordeal within the marriage was easier to cope with. Almost all of the participants felt that sharing their burden with their spouses and getting their support played a major role in their ability to keep hope alive during this time of tribulation.

\subsection{Sharing the Burden}

The participants expressed that in addition to the support of their spouses, the support of their doctors played a key role in coping with infertility.

"Well, look, it was actually my husband. He's been very supportive because he will watch the times they tell you when you take treatment, you got to watch the time. If you take seven o'clock this morning it gonna be the next morning seven o'clock, and he's never late on that, or it was always on time with him. So he was very supportive during treatment. He would also ask me if I need anything, he would make sure that I rest and take it easy no heavy housework, you know. He was very good in supporting me."

"Uhm, my husband and then after the implants I would say my sister and my female cousins. I had good support from my husband and close family."

"My husband, he make sure if I go anywhere he brings me home before the time, time was the essence, taking the injections and he was always very concerned and strict with the timing of injections?"

"My husband was my main source of support."

"My husband was the one person who supported me the most."

The participants described mixed feelings with regards to support by family members and friends. When the participants disclosed their infertility status, they either received a very strong support base or none at all from family and friends.

"Family in the way in which we grew up, they are very supportive. So neither of our families you know have been acting. They have been very supportive. And allowed us our space to talk about it or not. Then again we only surrounded ourselves by close family."

"Look, they can actually, I mean, disturb your feelings, hurt your emotions, and uhm, there could be a lot of 
things they can say or do to hurt you, you know, if people get to know that this is what you are. People won't see the sense that you are struggling and that you so much want a baby. They will do what they can to show you your weakness and make you feel your loss."

"I think in the society that I come from a woman only becomes a woman when she gets married and that elevates her to a certain status. And when she has children that elevate her to an even higher status. So, I think in my general society, the general circumstances I think that how society views woman falling pregnant. Then also there's this, you know, shame, like woman who struggle to fall pregnant or women who can't have children."

Since the experience of disclosure to family and friends were not positive, the participants resorted to social isolation and somehow chose to live life in a bubble.

\subsection{Living Life in a Bubble}

\section{1) Social isolation: "leave me alone"}

The participants resorted to isolating themselves from family functions and social gatherings as a means of coping with their infertility.

"At times it was easier to stay away because when I go to functions there are always questions about why are you not pregnant yet, have you been to the doctor, try another doctor, try this remedy and that remedy."

"It's really very stressful for me because I have to constantly endure these negative comments and it makes you feel more inferior and inadequate. And you know sometimes people mean well but the result of their interference has the same effect as someone who does not mean well."

These participants speak out about their frustration with having to endure the comments of relatives and friends. For these participants, the discussion about their infertility is stressful as it reinforces their inferiority and inadequacy as women. They regard the discussions as being an "interference" which has negative connotations and not regarded as measures that are helpful or positive. Even though they are aware that the intensions of relatives and friends may be good, they nevertheless describe their actions and the result of their actions as having the same effect as people who have intensions to be hurtful towards them. Another participant shares her experience with family and friends.

"I love my family and being with them and friends and all but it just gets too much watching other pregnant women. All the women gather around them, rub their belly or fuss around them and your infertility hits you in the centre of your being right down to the pit of your empty tummy. Ag! That feeling, that taste in your mouth lasts a long time and takes quite to while to pass."

\{Interviewer: Can you tell me more about that feeling?\}

"When this happens and it happens all the time, it really makes me depressed for weeks. Its not to say that I'm jealous or don't want other women to have children because I do its just that my feeling for wanting a child overwhelms me and that desire for my own child is intensified what this happens. This feeling is intensified to such a point that I can see pass my own pain and emptiness to partake in the joy of another woman who has managed to fall pregnant. You may think I'm jealous and envious and resentful, but I'm not. I do not have bad intensions about the pregnant person; really I don't its just all about me and my inadequacies."

This participant explains the struggle many infertile women bear. She describes her struggle to share in the joy of the birth a new life and her inability to transcend her own denial of conception. She describes the experience of being exposed to a pregnant women's delight as having a physiological effect on her by leaving an enduring "bad taste" in her mouth. She talks about been affected this way for weeks and as a result of this she is feeling depressed. Accompanying the depression was the innate yearning for her own biological child, which was manifested in what she describes as "infertility hits you in the centre of your being right down to the pit of your being". Clearly this description captures the pain and agony of her experience. For many of these women, the experience of living with infertility even in the company of loved ones can be a very lonely and painful experience, so much so that to isolate oneself from family functions and social gatherings feels less painful and agonising.

\section{2) Can't bear pregnant women and mothers}

Another strategy employed by some of the participants for coping with infertility was avoiding pregnant women and mothers and all activities related to pregnancy and honouring mothers, as it was just another reminder of their inability to conceive and their failure as women. For almost all of the participants, baby showers, Mother's Day and Father's Day were the most hard-hitting. Although these occasions are considered consumer- 
ist and not a recognised public holiday, it is nevertheless widely celebrated and yet another reminder to these women that they are failures.

"It is so difficult to get away from this pregnancy thing, it is everywhere. You walk to your letter box to fetch your letters you see a pregnant woman walking, you switch on your television you see a pregnant woman. Every now and then someone I know is having a baby shower for so and so and sometimes I get invited and sometimes not invited and then I only hear about it afterwards. Then again, I'm not sure if I want to be invited because whether I am or not it both feels bad. When I am invited and go to the baby shower, I feel terrible and come home depressed because even though I am happy for that person that is pregnant, it is not about her but about my inability to conceive and for weeks I am depressed and miserable. When I am not invited I also feel depressed and angry because I was 'excluded' from the occasion. Sometimes I feel almost as if I am not good not to be part of the celebration. I know, in my mind I know it is irrational but in my heart I feel this pain."

"I hate Mothers' Day and Fathers' Day because for me this is the official day to make an infertile person feel like a total failure. These days are not only to celebrate and honour mothers and fathers it is also there to dishonour childless couples. And every year I fall into this trap by spending the day licking my wounds and when things are really bad and I don't feel like facing the world then I make an excuse to get out of the mother's day lunch. All my friends and family know not to invite me to baby showers, I say straight 'no' I don't attend these things."

Both of these participants shared that they felt depressed on the occasions that celebrate Mother's Day, Father's Day and baby showers. The participant speaks quite candidly about her pain when attending baby showers and reveals that her feelings about not been invited do not make sense to her because either way she would have felt depressed. She talks about a "heart-brain split" whereby her mind tells her that she is being irrational but her heart feels the pain of being left out.

Another participant felt that Mother's Day and Father's Day is just another way to make infertile people feel inadequate and to reinforce the ideology of the value placed on children and childbearing. While the celebrated occasions are there to honour mother/fathers, at the same time these occasions provide an opportunity to discredit, dishonour, and bring shame to infertile people. The plight of infertility can often be experienced as very overwhelming. Another means of coping with this devastating ordeal is to employ escapism strategies such as avoiding pregnant women or women with young children or finding other goals in life [14].

\subsection{Escapism}

Escapism involves the practice of not thinking about infertility, motherhood, babies or any fertility issues. Some of the participants coped with infertility by exercising some form of escapism. For instance, when some of the participants were tired of being frustrated of their failed attempts to conceive, they often engaged in activities that kept them distracted from thinking about the infertility. Some of the participants said they worked more, engaged in shopping, sleeping and basically anything to keep their minds off it.

"Yes, I do work, I'm on the road, I just keep myself busy, keep myself busy all the time so that I don't need think about it."

"I just try to not think about babies and treatment itself and I just try to carry on with doing my work or whatever I was supposed to do. Like I said I have the support of my husband and that really helps me a lot."

"I just block it out and keep myself busy with things so that don't think about it."

"I was just kind of staying busy, and just keep going, I have a very busy life as it is, so I just carried on as normal. I go shopping; sleep a lot and just anything to keep busy."

"Oh yes shopping does come in, then my hubby says, "How is this gonna affect the bank balance?"(both laugh) because that makes me feel good... actually, just go out and go and shop...I just try to keep busy with things to pass the time really."

Lee et al. (2000) termed this escapism as "increasing space" which referred to as the infertile individual or couple increasing space between themselves and their fertility problems, usually by avoidance or keeping busy. Many of the participants in the study used a variety of coping strategies while living with infertility and all of them displayed great resilience in coping with infertility.

\subsection{Resilience}

An explicit characteristic of the participants is their resilience. They all displayed an inner strength that allowed 
them to cope with the infertility ordeal.

"I do believe that everything happens in your life for a reason. It makes me a stronger person and I am a very important person and I can't always have things when I want to and how I want it. There was also a good side that I've learnt. I don't really compare myself with other moms, I think it is mostly my friends that got children. When there is a new pregnancy or new birth, I can't do it, then I have to find a way to cope with it."

Their resilience is manifested in the self-dialogue that continues throughout their infertility experience. Participants often engage in self-talk, which is indicative of their ability to withstand the highs and lows of infertility. They are able to pick themselves up from a bad experience and move to the next stage feeling positive.

"Well the only thing is, the chances like the doctor has said, it makes you very excited cause, you don't have thoughts of even if they say the percentage are low, I think its about, thirty or, your chances of fertility is about fifty percent, forty five percent, I was still positive about it knowing that on the one hand we need to make eggs, so I wasn't thinking about anything that can go or should go wrong with that, I just stayed focused on the positive."

"It is like I am going to beat it, like I can beat it, because all they've told me in my particular case it is not like I can never have children, it is like you've looking at the side that you can have children, but we just haven't got it right yet. So to me I will have children, it drives me even more, like I will have children."

The participants drew on a strong sense of optimism that they will eventually be successful. Even when they were given the diagnosis they chose to focus on the positive aspects of what the doctor said and gave little consideration to the negative diagnosis.

\subsection{Discussion of Findings}

The participants approached fertility in a normative manner by assuming that conceiving a baby would be a natural and easy process. They consciously planned to fall pregnant and suspended the use of all forms of contraceptives. In efforts to enhance their fertility, the participants engaged in fertility promoting behaviours like eating healthily, and close monitoring of their menstrual and ovulation cycles. Initially, the participants did not think that their non-conception warranted medical investigation. However, after some time had lapsed, usually a year, the participants began to suspect a problem but often preferred to externalize the cause of their failure to conceive to stressful life events rather than accept a physiological cause.

The participants shared their experience of marital strain and their struggle to negotiate social acceptance in a society where fertility is highly valued and childlessness rebuked. They adjudicated that their bodies had failed them. The participants found themselves in a process of reconfiguring the fertile versus the infertile body. The renegotiation of the meaning of the body meant finding an identity space for being a woman and space for being childless at the same time. This sense of failure interrogated other aspects of their identity. As women and wives, it raised uncertainty about their sense of purpose within their families, social network, community and the world. It is evident that infertility is an all-encompassing experience that penetrates hurt, pain and loss and infiltrates into all aspects of an infertile couple's life. Infertility is often experienced as a life crisis, which are characterised, by emotional turbulence and cyclic feelings of hope and excitement and gloom and despair. Since the participants in this study believed that their true purpose in life was to become a mother, their experience of infertility has raised a sense of shock, denial, disappointment, self-doubt, failure, isolation, anger, blame and even depression. Several coping strategies were used; disclosure of their infertility status to family members and friends, sharing the burden, living in a bubble by avoiding pregnant women and mothers and withdrawing from social functions and family gatherings, increasing knowledge as a means of control and escapism. These coping mechanisms and strategies, coupled with the resilience displayed by these participants, aided the participants in coping with infertility. The inner strength that these women have should not be neglected as it is the buffer that provides the endurance which these women consistently display. These women utilised coping strategies that included social withdrawal, isolating themselves from social events and social gatherings. The participants employed strategies of escapism both on a psychological and physical level as a means of enduring and coping with the hardship of infertility. Drawing on their social networks, making tough decisions as to whether they should confide in their close friends and loved ones in disclosing their infertility status. This study has revealed that infertility is not an easy journey and coping with infertility requires the infertile couple to possess a strong sense of resilience and to surround themselves with solid social support that is supportive rather than obtrusive. 


\section{Conclusion}

Fertility specialists and health practitioners working at fertility clinics may benefit from the findings of studies of this nature. The entire process of infertility is characterised by intense emotions culminating in feelings of hope on one hand and total devastation on the other. Women in these situations find themselves having to negotiate with these binary emotions all the time. Experiencing a range of these emotions simultaneously places women in a fragile psychological emotional position and predisposes them to psychological difficulties. Becoming aware of the various emotional responses and challenges faced by the patients allows these specialists the insight to manage fertility cases more holistically and to realise the importance of being sensitive to the individual needs of women. It is a recommendation that studies of this nature be presented to fertility clinics so that a holistic treatment programme may be implemented with the aim of improving the experience of infertility treatment and care. This will allow patients to become more aware of what to expect and thus learn to employ better coping strategies. Infertile patients seeking to undergo these treatments may also be better prepared for the emotional costs that accompany these treatments. Furthermore, infertile women are individuals who have confronted loss, grief and failure and have informed our thinking about motherhood and infertility. There is a need to promote socially valued roles for women other than that of motherhood. Women should be valued for their individuality and their contribution to society rather than their reproductive ability.

\section{References}

[1] Joshi, H.L., Singh, H. and Bindu (2009) Psychological Distress, Coping and Subjective Wellbeing among Infertile Women. Journal of the Indian Academy of Applied Psychology, 35, 329-336.

[2] Wirtberg, I. (2006) His and Her Childlessness. Dissertation Karolinska Institute, University of Sweden, Stockholm.

[3] Ndaba, N. (1994) The Experiences of Infertile African Women in Durban. Unpublished Masters’ Dissertation, University of Natal, South Africa.

[4] Ulrich, M. and Weatherall, A. (2000) Motherhood and Infertility: Motherhood through the Lens of Infertility. Feminism \& Psychology, 10, 323-336. http://dx.doi.org/10.1177/0959353500010003003

[5] Wager, M. (2000) Childless by Choice? Ambivalence and the Female Identity. Feminism \& Psychology, 10, $389-395$. http://dx.doi.org/10.1177/0959353500010003010

[6] Woollett, A. and Boyle, M. (2000) Reproduction, Women’s Lives and Subjectivities. Feminism \& Psychology, 10, 307-311. http://dx.doi.org/10.1177/0959353500010003001

[7] Van Balen, F. and Gerrits, T. (2001) Quality of Infertility Care in Poor-Resource Areas and the Introduction of New Reproductive Technologies. Human Reproduction, 16, 215-219. http://dx.doi.org/10.1093/humrep/16.2.215

[8] Klock, S. (2011) Psychological Issues Related to Infertility. Global Library of Women’s Medicine. http://dx.doi.org/10.3843/GLOWM.10413

[9] Seibel, M.M. and Taymor, M.L. (1982) Emotional Aspects in Infertility. Fertility and Sterility, 37, 137-145.

[10] Domar, A.D., Zuttermeister, P.C. and Friedman, R. (1993) The Psychological Impact of Infertility: A Comparison with Patients with Other Medical Conditions. Journal of Psychosomatic Obstetrics and Gynaecology, 14, 45-52.

[11] Boonmongkon, P. (2002) Family Networks and Support to Infertile People. In: Vayena, E., Rowe, P.J. and Griffin, P.D., Eds., Current Practices and Controversies in Assisted Reproduction, World Health Organisation (WHO), Geneva.

[12] Hasty, J.A. (2011) Fundamentally Flawed: Finding Peace and Hope in Infertility. New Book Publishing.com, USA.

[13] Kubler-Ross, E. (1969) On Death and Dying. Macmillan, New York.

[14] Abbey, A. (2000) Adjusting to Infertility Loss and Trauma: General and Close. Relationship Perspectives, 12, 331-344.

[15] Cooper, R. (2007) When the Professional Is Personal. Forum, 33, 5-6.

[16] Pedro, A.S. (2001) The Emotional Experiences of Infertile Couples. Unpublished Thesis, University of the Western Cape, Bellville.

[17] Pedro, A.S. (2004) A Discourse Analysis of South African Infertile Women. Unpublished Thesis, University of the Western Cape, Bellville.

[18] Larsen, U. (2000) Infertility in Central Africa. Tropical Medicine and International Health, 8, 354-367. http://dx.doi.org/10.1046/j.1365-3156.2003.01039.x

[19] Schmidt, L., Holstein, B., Christensen, U. and Boivin, J. (2005) Does Infertility Cause Marital Benefit? An Epidemiological Study of 2250 Women and Men in Fertility Treatment. Patient Education \& Counselling, 59, 244-251. 
http://dx.doi.org/10.1016/j.pec.2005.07.015

[20] Lee, T.E., Sun, G.H., Chao, S.C. and Chen, C.C. (2000) Development of the Coping Scale for Infertile Couples. Archives of Andrology, 45, 149-154. http://dx.doi.org/10.1080/01485010050193922

[21] Miall, C.E. (1986) The Stigma of Involuntary Childlessness. Social Problems, 33, 268-282.

http://dx.doi.org/10.2307/800719 
Scientific Research Publishing (SCIRP) is one of the largest Open Access journal publishers. It is currently publishing more than 200 open access, online, peer-reviewed journals covering a wide range of academic disciplines. SCIRP serves the worldwide academic communities and contributes to the progress and application of science with its publication.

Other selected journals from SCIRP are listed as below. Submit your manuscript to us via either submit@scirp.org or Online Submission Portal.
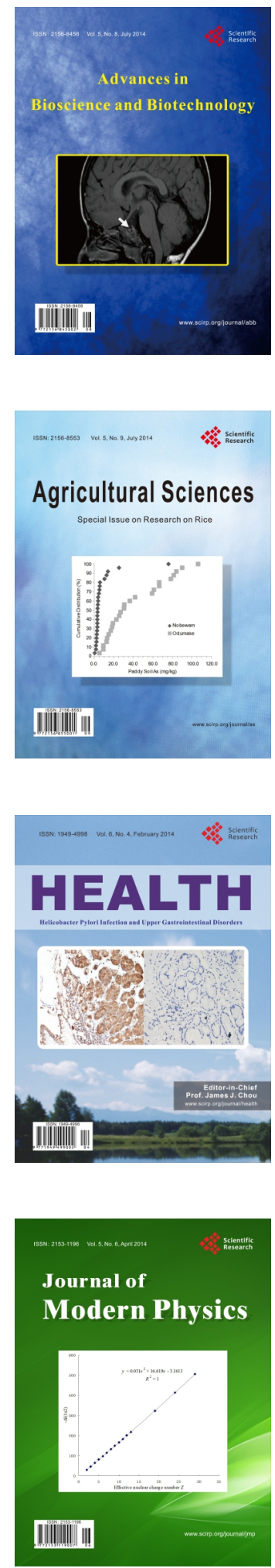
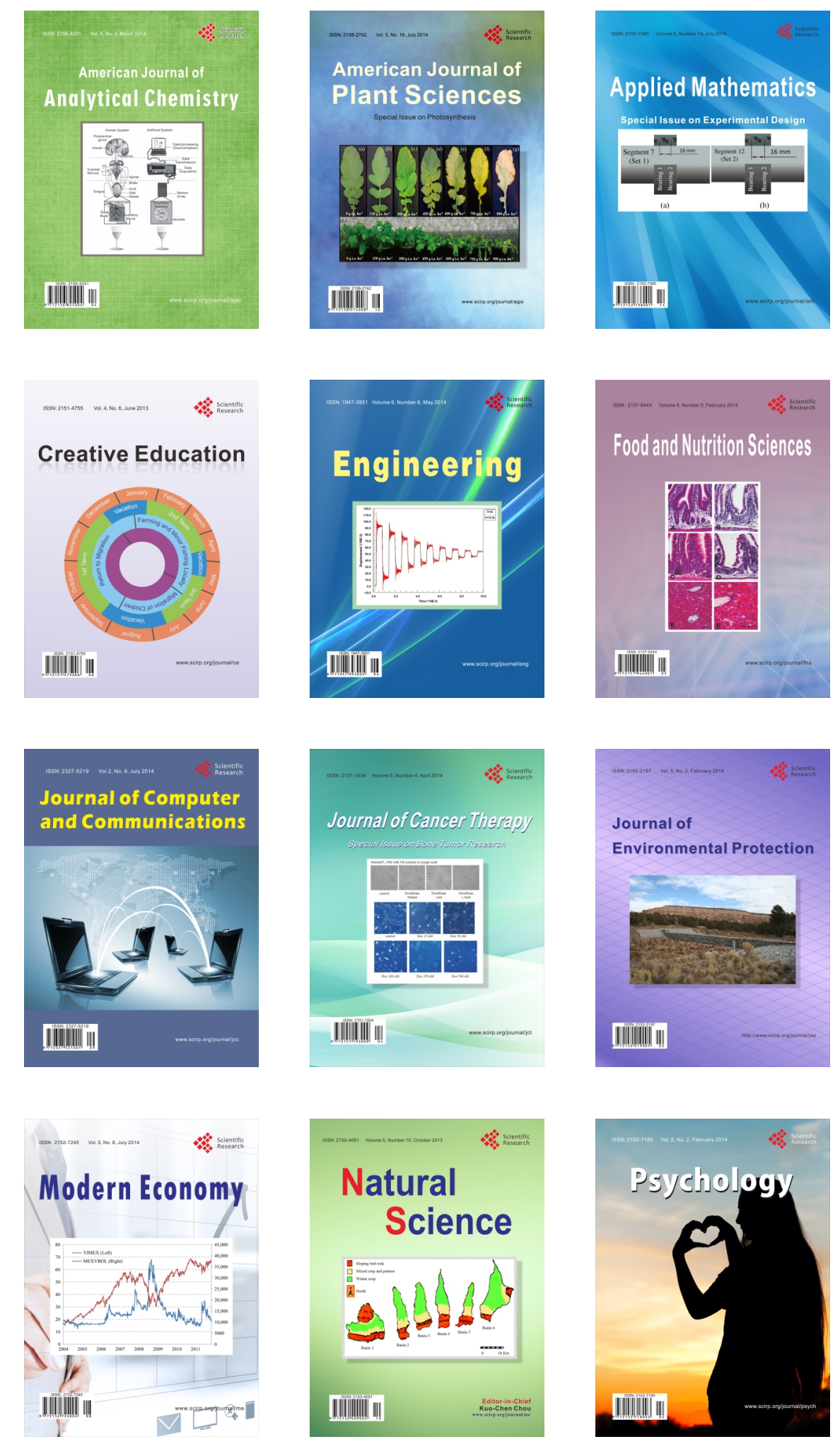